\title{
The Effect of Myristica fragrans on Texture Properties and Shelf-Life of Innovative Chewable Gel Tablets
}

\author{
Inga Matulyte ${ }^{1,2} \mathbb{D}$, Akvile Mataraite ${ }^{3} \mathbb{D}$, Saule Velziene ${ }^{1}$ and Jurga Bernatoniene ${ }^{1,2, *(\mathbb{D})}$ \\ 1 Department of Drug Technology and Social Pharmacy, Lithuanian University of Health Sciences, \\ LT-50161 Kaunas, Lithuania; inga.matulyte@lsmu.lt (I.M.); saule.velziene@lsmuni.lt (S.V.) \\ 2 Institute of Pharmaceutical Technologies, Lithuanian University of Health Sciences, \\ LT-50161 Kaunas, Lithuania \\ 3 Faculty of Medicine, Lithuanian University of Health Sciences, LT-44307 Kaunas, Lithuania; \\ akvimata0128@kmu.lt \\ * Correspondence: jurga.bernatoniene@lsmuni.lt; Tel.: +370-60063349
}

Citation: Matulyte, I.; Mataraite, A.; Velziene, S.; Bernatoniene, J. The Effect of Myristica fragrans on Texture Properties and Shelf-Life of Innovative Chewable Gel Tablets. Pharmaceutics 2021, 13, 238 https://doi.org/10.3390/ pharmaceutics 13020238

Academic Editor: Donatella Paolino Received: 8 January 2021

Accepted: 3 February 2021

Published: 9 February 2021

Publisher's Note: MDPI stays neutral with regard to jurisdictional claims in published maps and institutional affiliations.

Copyright: (c) 2021 by the authors. Licensee MDPI, Basel, Switzerland. This article is an open access article distributed under the terms and conditions of the Creative Commons Attribution (CC BY) license (https:// creativecommons.org/licenses/by/ $4.0 /)$.

\begin{abstract}
Chewable gel tablets are an underdeveloped subject, even though there are many simple chewable tablets and gummy candies in the food and pharmaceutical industries. Chewable gel tablets are not as sweet, they can have an active substance, pharmacological effect, and a value of nutrition. The aim of this study was to prepare gelatin-based chewable tablets with Myristica fragrans as a preservative and to determine the shelf-life variability depending on storage conditions, and to evaluate texture changes. Firmness and springiness of gel tablets were measured by a texture analyzer and compared between different storage conditions and the shelf-life of tablets was established by mold growing time. Chewable gel tablets were prepared by using silicone form. Mold was most likely to grow on tablets that have been packaged in squeezable bags (after 14 days $60 \%$ of all formulations had a mold, $p<0.05$ ). The most stable tablets (over 180 days) were in sealed boxes and contained nutmeg essential oil or its solution, or ethanolic nutmeg extract. The gel tablets' firmness increased about 4 times when they were stored in opened plastic boxes and their springiness decreased about 1.65 times after 28 days in the mentioned conditions, $p<0.05$. Nutmeg hydrolat had the highest influence on texture variation $(p<0.05)$.
\end{abstract}

Keywords: chewable gel tablet; nutmeg essential oil; gel; mold; firmness; springiness; gelatin; preservative; pharmaceutical research

\section{Introduction}

Chewable tablets are a popular dosage form for children, elderly patients or for those who have swallowing disorders. Water is not required for the use of these tablets because they are chewed and saliva moisturizes the tablet mass, which is then easily swallowed, so it is comfortable to use on a journey or in places where it is difficult to get water $[1,2]$. The most popular chewable tablets are tablets such as paracetamol, acetylsalicylic acid, ibuprofen [3] or other tablets which have an active substance and many excipients, and are mostly opaque or white in color, and are prepared by compression. Another group of chewable tablets are chewable gel tablets which are commonly referred to as gummies $[4,5]$. These tablets are prepared by using forms (silicone, metal or other) and are not compressed by tablet machines' punches such as simple (uncoated, coated, soluble or chewable) tablets which are mentioned in the European Pharmacopoeia monograph of Tablets $[2,5,6]$.

Chewable tablets have a pleasant taste and leave no bitterness or an unpleasant taste after eaten. They have many advantages compared to another pharmaceutical forms: they are easy to administrate, water is unnecessary, teaspoons or other cutlery are not required; therapeutic effect of an active substance can be terminated by discarding it before complete ingestion, and they can be used for systemic drug delivery [2,7].

Gel tablets are prepared by using excipients which have gelling properties (gelatin, pectin, tragacanth, starch, agar, and many others). Most gelling agents are polysaccharides 
and polymers which form gels $[2,8,9]$. Gelatin is a natural material made from pork skin, beef hide or bones, and its extraction and consumption are growing every year (from 130 tons in 1974 to 305 tons in 2005) [10]. Gelatin made from fish is an alternative to pescatarians though its cost is 4-5-times higher than porcine or bovine gelatin [11]. All gelatin types have many amino acids, approximately $90 \%$ protein, which is a good food supplement $[10,11]$. Gelatin is widely used not only in the food industry but also in the pharmaceutical industry for the making of gelatin capsules and gelatin-based plasma substitutes. Additionally, it is used as an emulsifier, a microencapsulating agent or a stabilizer in some vaccines, and as a gelling agent $[10,12,13]$. To prepare a biopolymer (gelatin) solution, the use of water is required but it is a good media for microorganisms. There are several methods to prepare a gelatin-based solution but the most popular is to pour cold water on gelatin and leave it for several minutes to swell and then heat it to dissolve the gelatin. Gelatin forms colloidal solutions with water and gels of varying stiffness are produced depending on the concentration $[4,5,10,12,14]$.

Chewable tablets have a sweetener that ensures a good taste. In the food industry there are many sweeteners (natural, semi-natural or chemical). Each sweetener has its advantages and disadvantages, such as sucrose which is a natural sugar produced from sugar beets or sugar canes. It is easily absorbed and provides energy $[1,4,15,16]$. A huge amount of sucrose in jelly can crystallize and form a layer of sugar on top. To avoid this, polyols are used (sorbitol, glycerol or others), they do not let the sugar crystals to form $[1,17]$. Artificial sweeteners, although some are sweeter than sucrose, cannot deceive the brain and an organism understands what type of calories were gained and which hormones have to be released from the cells in order to break down the consumed sweeteners. These artificial sweeteners can lead to seizures, headaches, and attention deficit disorders (aspartame as an example) [18].

To manufacture palatable chewable tablets and for them to stand out in the market, sweeteners are not the only substances that should be used as a taste agent; flavorings may be used as well to refer to a specific combined sensation of taste and smell [4,7]. Natural flavors that could be used are herbs, spices, bee products, their extracts, syrups or other forms [19]. They do not only have flavor or taste (honey, vanilla, thyme) but can also create a specific color (acai berry, blueberry, orange) $[4,15,20]$.

Chewable gel tablets have water in their composition which is a good media for bacteria and to prevent the growth of bacteria, it is important to use huge amounts of sweeteners or preservatives. The sweeteners' amount substitutes water (however, it is not always sufficient as a preservative). Nowadays, it is a trend to consume less sugars, so if their amount is reduced, other materials have to replace them. The preservatives such as citric acid reduce $\mathrm{pH}$ values and create an undesirable media for the growth of microorganisms. Other preservatives can kill the microorganisms and prolong a product's shelf-life [21]. Citric acid and apple acid are the most commonly used to adjust the $\mathrm{pH}$ in food products, and sodium benzoate or potassium sorbate are usually used as preservatives, but now there is a new trend to use natural preservatives such as spices and fruit peels [4,22-24].

Additionally, microbial contamination is possible due to the contamination of the equipment and the environment. A microbial contamination can do damage to products (reduce shelf-life, change appearance, color, taste). Pharmaceutical forms (solid, semi-solid or liquid) are prone to microbial spoilage or degradation. Any improper packaging and consumption only increase contamination [25]. To protect products from contamination it is necessary to use cleaned devices and to follow good manufacturing practice rules [26,27].

Nutmeg has antioxidant and antimicrobial properties which can be used to protect chewable gel tablets from mold (fungal growth). It has an effect on Bacillus subtilis, Staphylococcus aureus, Shigella dysteriae, Aspergillus niger, also, Myristica fragrans extracts prepared in different conditions have many other activities against other bacteria [22,28-31]. Additionally, it was determined that nutmeg essential oil has effect on suppressed Enterococcus faecalis, Streptococcus mutans (referent), and Pasteurella multocida bacteria [32]. Talking about 
Enterococcus faecalis, it is related to oral diseases, such as caries, endodontic infections, periodontitis, and peri-implantitis [33,34]. Using natural essential oil or other materials from nature can help reduce bacterial growth. Antioxidant compounds in nutmeg seeds are: myristphenone, phenolic volatile compounds, phenolic acid (caffeic acid), flavanols (catechin). Compared with other spices and herbs, nutmeg has more than $50 \%$ activity of inhibition of DPPH (2,2-diphenyl-1-picrylhydrazyl) [22,35]. Nutmeg can not only preserve a product and prolong its shelf life (which is very important for chewable gel tablets that have water in their composition) but also it decreases bacterial growth in mouth and binds free radicals, this adds additional benefits.

Chewable gel tablets with a natural preservative (such as Myristica fragrans) are an innovative pharmaceutical form which can be used as a food supplement or a medical device, and it can have less sugar or sweetness because the natural preservative can prolong shelf-life of gel tablets and it can also substitute the chemical preservative. Nowadays there is a trend of "less sugar" or "natural products", "from nature/together with nature", so natural plant as a preservative is a novelty, moreover, it also has some pharmacological effects (antioxidant, anti-inflammatory, antibacterial), and it is a new area in the manufacture and texture analysis of property differences of chewable gel tablets.

The aim was to develop chewable gelatin-based tablets with natural materials used for taste and flavor and to compare the influence of Myristica fragrans seed extracts, essential oil, and hydrolat as preservatives to prolong tablets' shelf life according to the time of onset of mold on the tablets, and to compare the influence of storage conditions on the texture of gel tablets.

\section{Materials and Methods}

\subsection{Materials}

Chewable gel tablets basis was prepared using gelatin (Carl Roth $\mathrm{GmbH}+\mathrm{Co}$. KG, Karlsruhe, Germany), distilled water (LUHS laboratory, Kaunas, Lithuania), and glycerol (99+\% vegetable origin; Chem-Lab, Zedelgem, Belgium). Thyme herb (A. Karvelis therapy-phytotherapy company, Švenčionys, Lithuania) and sugar (Pfeifer and Langen Marketing Sp., Poznan, Poland) were used for flavor, color, and odor. Sodium benzoate (Berchem, city, Lithuania), 96\% ethanol (Vilniaus degtinè, Vilnius, Lithuania), citric acid (Carl Roth $\mathrm{GmbH}+\mathrm{Co} . \mathrm{KG}$, Karlsruhe, Germany), and Myristica fragrans seed (from Grenada; supplier Spaisvile, Pašaltuonys, Lithuania) extracts, hydrolat and essential oil were used as preservatives. Chewable gel tablets were prepared using silicone gummy bear form. Different concentrations of ethanol were used as an additive material for extracts.

All nutmeg seed products and thyme syrup were prepared in Lithuanian University of Health Sciences, Department of Drug Technology and Social Pharmacy.

\subsection{Thyme Syrup Preparation}

Thyme extract was prepared from thyme herbs and $20 \%$ ethanol by using an ultrasound bath. After $30 \mathrm{~min}$, the extract was filtered and was left to settle down. Ethanolic extract was gained from the material in a ratio of 1:1. Thyme extract (three parts) was mixed with $64 \%$ of sugar syrup (17 parts) and stored in a refrigerator.

\subsection{Nutmeg Seed Products Preparation}

Nutmeg seed extracts were prepared as follows: one part of nutmeg seed powder was put into the flask and 20 parts of water or $70 \%$ ethanol ( 20 parts) were poured in. The flask with these contents was inserted into an ultrasound bath, after $30 \mathrm{~min}$. the extracts were filtered and poured in a bottle, and stored in a refrigerator.

Essential oil from Myristica fragrans seeds was prepared by using a modified Clevengertype apparatus [36]. Fifteen grams of nutmeg powder and $300 \mathrm{~mL}$ of distilled water were used for the preparation of the essential oil. The hydrodistillation process took four hours. Hydrolat was collected as a by-product. Both samples were stored in a refrigerator, in a dark glass bottle. 


\subsection{Chewable Gel Tablets' Preparation and Compositions}

The pilot-study was performed with different amounts of gelatin, water and thyme syrup. Five different compositions were prepared and one base of chewable tablets was selected based on visual and organoleptic methods.

The samples of gel tablets were prepared as follows: gelatin was mixed with water and glycerol solution, and stored for 10-15 minutes to swell. After swelling, the gelatin solution was heated in a water bath $\left(60^{\circ} \mathrm{C}\right)$. Thyme syrup (room temperature) was added in the gelatin solution and mixed, then the preservative was added. The chewable gel tablets' mass was poured in silicone forms and left for 24 hours to solidify $\left(20 \pm 5^{\circ} \mathrm{C}\right)$. Gel tablets were removed from the forms and further investigations were carried out. The gel tablets' compositions are presented in Table 1.

The gel tablets of each series were stored in five different locations: in plastic boxes in a refrigerator at $8{ }^{\circ} \mathrm{C}(\mathrm{PBR})$ and in a freezer at $-15^{\circ} \mathrm{C}(\mathrm{PBF})$, in a squeezable plastic bag (SR) and on an opened plastic pallet (OR), and in a closed plastic box (CR) at room temperature $\left(20 \pm 5^{\circ} \mathrm{C}\right)$.

\subsection{Chewable Gel Tablets' Physical Parameters: Mass Change, Firmness and Springiness}

Throughout the study, the mass of gummies was measured and the mass loss with mass variation were calculated for all series of gel tablets. Chewable gel tablets were retrieved from the freezer and kept at room temperature for $30 \mathrm{~min}$ and then weighed. The influence of the storage conditions on the weight of the gel tablets was determined.

Chewable gel tablets' firmness and springiness were measured by texture analyzer TA.XT.plus (Texture Technologies, Brewster, NY, USA). The "Gummy confectionery" test was chosen. Parameters of the test: return speed $10 \mathrm{~mm} / \mathrm{s}$; force $1 \mathrm{~g}$; strain $50 \%$; pre-test $1.00 \mathrm{~mm} / \mathrm{s}$ test speed $1.00 \mathrm{~mm} / \mathrm{s}$; post-test speed $10 \mathrm{~mm} / \mathrm{s}$; hold time $60 \mathrm{~s}$; and trigger force $5.0 \mathrm{~g}$. Changes of texture of the chewable gel tablets were analyzed after one day and one month for the OR series gel tablets.

\subsection{Chewable Gel Tablets' Quality Determination}

The quality of the gel tablets was assessed by the appearance of mold (assayed fungal growth during storage) [15]. The longer the gel tablets do not mold, the more effectively the preservative acts against microorganisms. The influence of preservatives on the quality of the gel tablets was determined during the stability study: the days after which mold began to grow on the chewable gel tablets in a plastic box (CR) or the ones stored in the refrigerator (PBR) were counted.

\subsection{Microbial Contamination of Equipment}

Microbial species were selected according to a Pharmacopoeia Article (5.1.4., Microbiological quality of non-sterile pharmaceutical preparations and substances for pharmaceutical use-“'Special Ph. Eur. Provision for oral dosage forms containing raw materials of natural (animal, vegetal or mineral) origin for which antimicrobial pretreatment is not feasible and for which the competent authority accepts TAMC (total aerobic microbial count) of the raw material exceeding $10^{3} \mathrm{CFU} / \mathrm{g}$ or $\mathrm{CFU} / \mathrm{mL}^{\prime \prime}$ ) and the swab samples were taken from the equipment and containers. All tests of microbial growth were performed according to European Pharmacopoeia methods [37,38].

Before research, tools and equipment were cleaned with $96 \%$ ethanol, work was done with gloves. Chewable gel tablets were manufactured and tested according to the rules of good manufacturing practice.

\subsection{Statistical Analysis}

Data are presented as the mean $\pm \mathrm{SD}$. Statistical analysis was performed using Student's $t$ test. The results were significant when $p<0.05$. 
Table 1. Chewable gel tablets' composition.

\begin{tabular}{|c|c|c|c|c|c|c|c|c|c|c|}
\hline \multirow[t]{2}{*}{ Ingredients } & \multicolumn{10}{|c|}{ Samples Series } \\
\hline & G0 & G1 & $\mathrm{Sb}$ & E & $\mathrm{C}$ & Ae & Ee & Eo & Eos & $\mathbf{H}$ \\
\hline Gelatin $(\mathrm{g})$ & 7.0 & 7.0 & 7.0 & 7.0 & 7.0 & 7.0 & 7.0 & 7.0 & 7.0 & 7.0 \\
\hline Glycerol (g) & - & 5.0 & 5.0 & 5.0 & 5.0 & 5.0 & 5.0 & 5.0 & 5.0 & 5.0 \\
\hline Thyme syrup (g) & 25.0 & 22.0 & 22.0 & 22.0 & 22.0 & 22.0 & 22.0 & 22.0 & 22.0 & 22.0 \\
\hline Sodium benzoate solution $5 \%(\mathrm{~mL})$ & - & - & 1.0 & - & - & - & - & - & - & - \\
\hline $96 \%$ ethanol $(\mathrm{mL})$ & - & - & - & 1.0 & - & - & - & - & - & - \\
\hline Citric acid $50 \%$ solution $(\mathrm{mL})$ & - & - & - & - & 1.0 & - & - & - & - & - \\
\hline Aqueous nutmeg extract (mL) & - & - & - & - & - & 1.0 & - & - & - & - \\
\hline Ethanol nutmeg extract $(\mathrm{mL})$ & - & - & - & - & - & - & 1.0 & - & - & - \\
\hline Nutmeg essential oil $(\mu \mathrm{L})$ & - & - & - & - & - & - & - & 10.0 & - & - \\
\hline $\begin{array}{l}\text { Ethanol nutmeg essential oil 10\% } \\
\text { solution }(\mathrm{mL})\end{array}$ & - & - & - & - & - & - & - & - & 1.0 & - \\
\hline
\end{tabular}




\section{Results and Discussion}

\subsection{Chewable Gel Tablets' Composition}

A pilot-study was performed and the tablet base was selected before starting the study on the influence of nutmeg as a preservative on the quality of chewable tablets. The primary mass of chewable tablets with different gelatin concentrations (five compositions) was prepared and the G0 composition (Table 1) was selected according to the best physical parameters, taste and sensation, and a study was initiated with different preservatives. Gelatin concentration in five bases was from $7.69 \%$ to $15.38 \%$ and the best chewable gel tablets' base was determined with $13.46 \%$ of gelatin. In the Morten et al. (2018) study on gelatin-based pharmaceutical oral formulation, $8.8-10 \%$ concentration of gelatin was used [39]. Concentrations of gelatin can vary greatly depending on which gelatin is selected, there are many categories of gelatin which can be used in food or pharmaceutical industry [10]. Gelatin of different hardening strength, purity and bloom number is used in different studies. To prepare gummy candies, the Pizzoni et al. (2015) study of gummy candies with strawberry flavors used $6.5 \%$ of gelatin, and the Deleris et al. (2011) study about candies and aroma release dynamic used $0-15 \%$ of gelatin $[40,41]$. Chewable gel tablets are similar to gummies or candies, but they differ from them - they are eaten not as a desert but as a food supplement or a medical substance, and they have a medical and nutrition purpose because they are equivalent to chewable tablets which have a recognition in the European Pharmacopoeia [6].

After evaluating the composition of G0, it was observed that after some time the sugar on the surface of the chewable tablets begins to crystallize, therefore glycerol was added to the composition. Glycerol and other polyols are used as additives to protect from sucrose crystallization $[2,17,42,43]$. In this research $9.61 \%$ of glycerol was used, which not only protects from sugar crystallization, but also gives a sweet taste for the tablets [44]. Glycerol also protects chewable tablets from water loss and the mass of tablets does not change a lot when stored in an open package.

All chewable gelatin-based tablets had thyme syrup in composition. Thyme (Thyme vulgaris L.) herb has antiseptic and tonic effects and today it is used as a respiratory remedy which can reduce cough. Extracts, essential oil or a tea can be produced from its herb. Thyme gives an acceptable flavor for food, medicine and cosmetics. Chewing tablets with thyme (syrup was prepared from liquid thyme extract) can decrease the amount of microbes in the mouth. In traditional medicine, thyme was used as an antiseptic, antispasmodic, antitussive, antifungal, antioxidative material [45,46]. Thyme was chosen because of its wide pharmacological properties and as a flavor and color corrector in chewable gel tablets. All chewable tablets were yellow (amber) in color and had a pleasant taste apart from the fact that the used preservatives changed the transparency of the tablets (Figure 1).

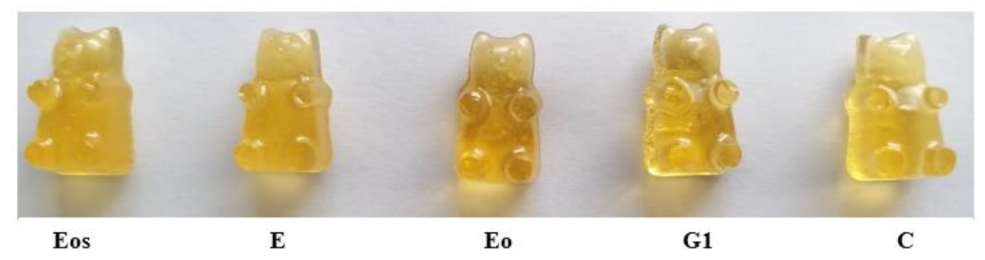

Figure 1. Chewable gel tablets' (Eos, E, Eo, G1, C) color pallet. The chewable tablets' composition code is given in Table 1.

Three tablets (Eo, G1 and C) of five (in Figure 1) were transparent, the Eo tablet was of the darkest color compared with all other chewable tablets' composition, which are presented in Figure 1. The Eos and E tablets were opaque, and a difference in the color of the gelatin-based tablets with the use of ethanolic extract or ethanolic essential oil solution was not found. This picture shows how different the colors of gel tablets can be by using a different preservative and its forms. All tablets (10 compositions) were yellow or amber color with a different undertone. 


\subsection{Chewable Gel Tablets' Weight Variation and Quality}

The mass changes in different storage locations were determined. All chewable gel tablets were weighed for four weeks and the differences of mass are presented in Figure 2. In Figure $2 \mathrm{~A}$, the mass variation in a room temperature in an open plastic bag is presented.
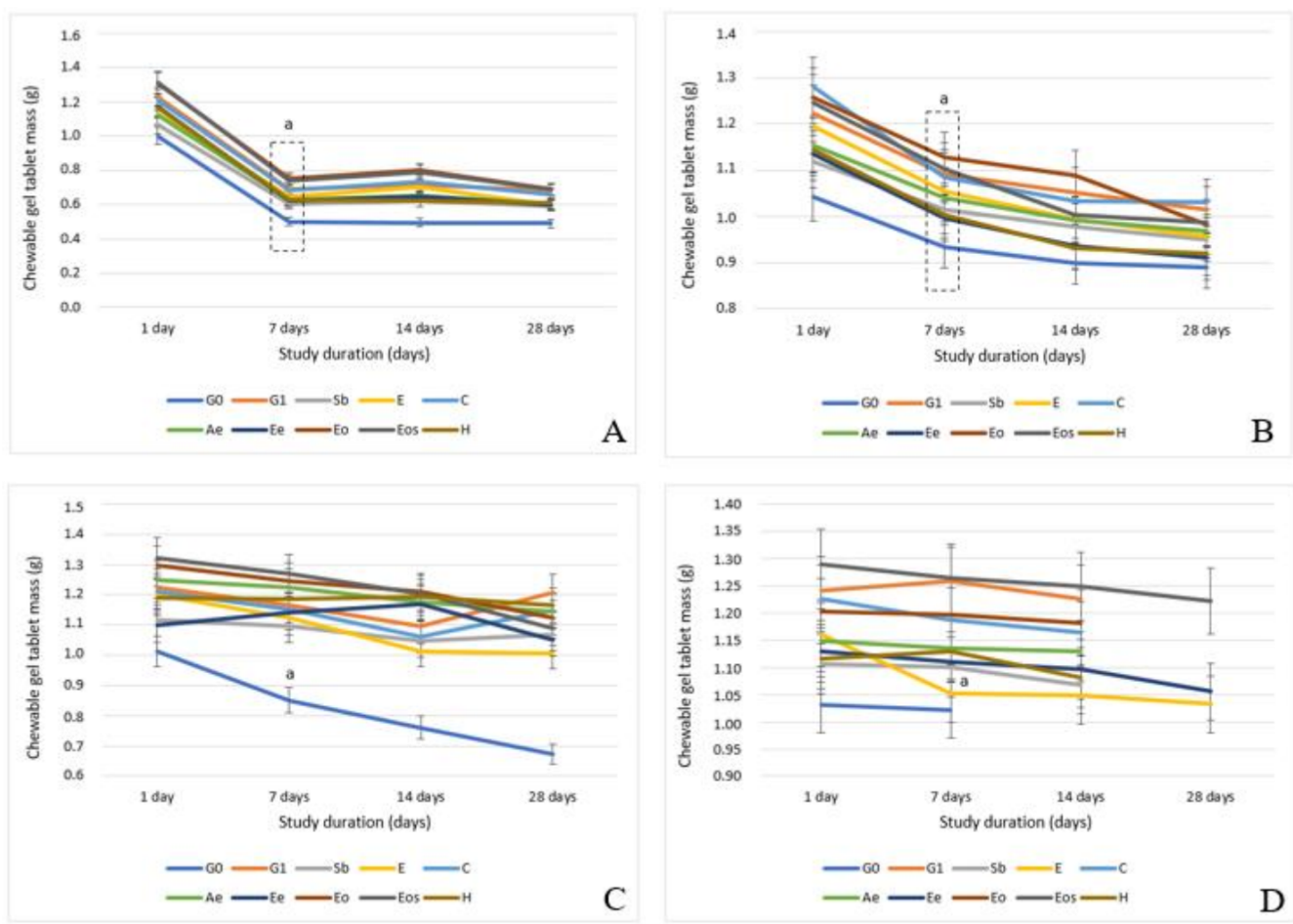

Figure 2. Chewable gel tablets' mass variation: (A) in an open plastic bag at room temperature (OR); (B) in a plastic box in a freezer (PBF); (C) in a plastic box in a refrigerator (PBR); (D) in a squeezable plastic bag at room temperature (BR), the expired curve in (D) shows that the tablets became moldy and were not weighed; $n=8 ; \mathrm{a}-p<0.05$ vs. mass after 1 day.

All samples' tablets (Figure 2A) weighed from $1.001 \pm 0.054 \mathrm{~g}$ to $1.314 \pm 0.039 \mathrm{~g}$ after one day, after a month (28 days) the tablets' mass interval was from $0.491 \pm 0.027 \mathrm{~g}$ to $0.788 \pm 0.033 \mathrm{~g}$. Certain storage conditions (temperature $20 \pm 5{ }^{\circ} \mathrm{C}$ and an opened box) caused the tablets to lose from $44.08 \%$ to $50.95 \%$ of their weight- the water in the tablets evaporated and the texture changed. In this study, it was observed that the tablets containing glycerol (all except G0) increased in weight after two weeks (this was due to the increased humidity in the room due to changed weather conditions). Glycerol attracted moisture from the environment to the tablets. Based on the study by Ramos et al. (2013), the moisture in the films varies depending on the glycerol concentration (from $17.91 \%$ to $21.71 \%$, glycerol concentrations $40-60 \%$ ) [47].

Moreover, tablets without glycerol had the smallest mass and were harder than gel tablets containing glycerol. Keeping chewable gel tablets in an open bag at room temperature is a wrong decision because they can lose not only water but also their active substances, which are volatile, and the texture of tablets are too hard to be chewed, although after 6 months all of the tablets remained unaffected by a mold.

Chewable gel tablets in a refrigerator (PBR) and a freezer (PBF) were kept in these conditions for one month. Before weighing the tablets, they were taken out from a refrigerator/freezer and left for 30 minutes in a room temperature (in a closed container). Then the tablets were weighed and the results are presented in Figure 2B,C.

Chewable gel tablets from the freezer (PBF, Figure 2B) lost from $15.01 \%$ to $21.94 \%$ of their mass after 28 days. The highest amount of water and other liquid material was lost from Eo, Eos, Ee, and E samples. All samples had essential oil or ethanol extract 
which can evaporate together with water therefore they have more changes in mass. The lowest mass variation was determined in G0 and $\mathrm{Sb}, 14.67 \%$ and $15.01 \%$, respectively. The tablets without glycerol from a freezer had the lowest mass variation. It can be concluded that freezing and thawing have the lowest effect on these gel tablets because only water evaporates and glycerol does not attract moisture from the environment since the temperature is too low (water is frozen) and the thawing time is too short for all of the formulations. Glycerol amount in these chewable gel tablets was $9.6 \%$. Based on the literature, $10 \%$ glycerol solution's freezing temperature (a point when the solution freezes) is $-1.6{ }^{\circ} \mathrm{C}[48,49]$. In this study the temperature was $-15^{\circ} \mathrm{C}$ so glycerol also froze and there was no incidence of moisture attraction from the environment.

Comparing the weight loss with the results gained from the gel tablets kept in refrigerator (PBR, Figure 2C), the G0 gel tablets lost over 33\% of mass and the other samples lost less than $18 \%$ of their weight (tablets which have essential oil or ethanol in their composition lost more than $10 \%$ of their content). It was observed that glycerol attracted moisture to the gel tablets, but no correlation was found between the study duration and weight change, some weight variations were determined in 7-14 days interval, others-14-28 days.

The direct effect of preservatives on the changes in tablet weight was not determined, unless the preservative was a volatile compound (essential oil, ethanol)—they evaporated under environmental conditions.

The smallest changes in mass were determined in a squeezable plastic bag (BR, Figure 2D) and in a closed plastic box (CR) at room temperature (this sample had less variation so data are not presented separately).

In a squeezable plastic bag as a storage location, it was determined that the gel tablets in there had the most variable shelf-life. In SR conditions, 70\% of the samples developed a mold after 14 days (sample G0 earlier). Only three samples (E, Ee, and Eos, Figure 2D) did not have a mold after 28 days. The Ee and Eos samples were stable for 75 days and the $\mathrm{E}$ for 52 days. These results show that ethanol and nutmeg ethanolic extract or nutmeg essential oil ethanolic solution have a higher influence on chewable gel tablets' shelf-life than sodium benzoate, citric acid or other solutions. These results (SR) were influenced by the chosen packaging (squeezable bag, Figure 3) because results in a plastic box at room temperature (CR) were different. The mass variation (Figure 4) was smallest and the shelf-life was longest in CR conditions (Figure 5).
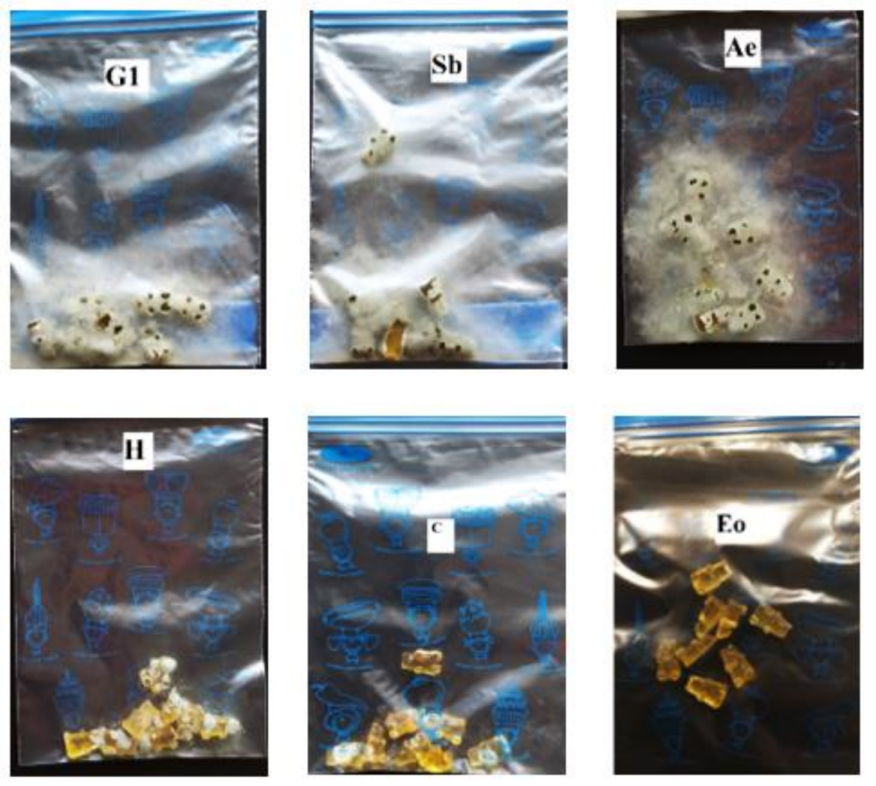

Figure 3. Mold growth on chewable gel tablets (G1, Sb, Ae, H, C, and Eo) after 52 days, $n=8$ (number of tablets in the plastic bag). 


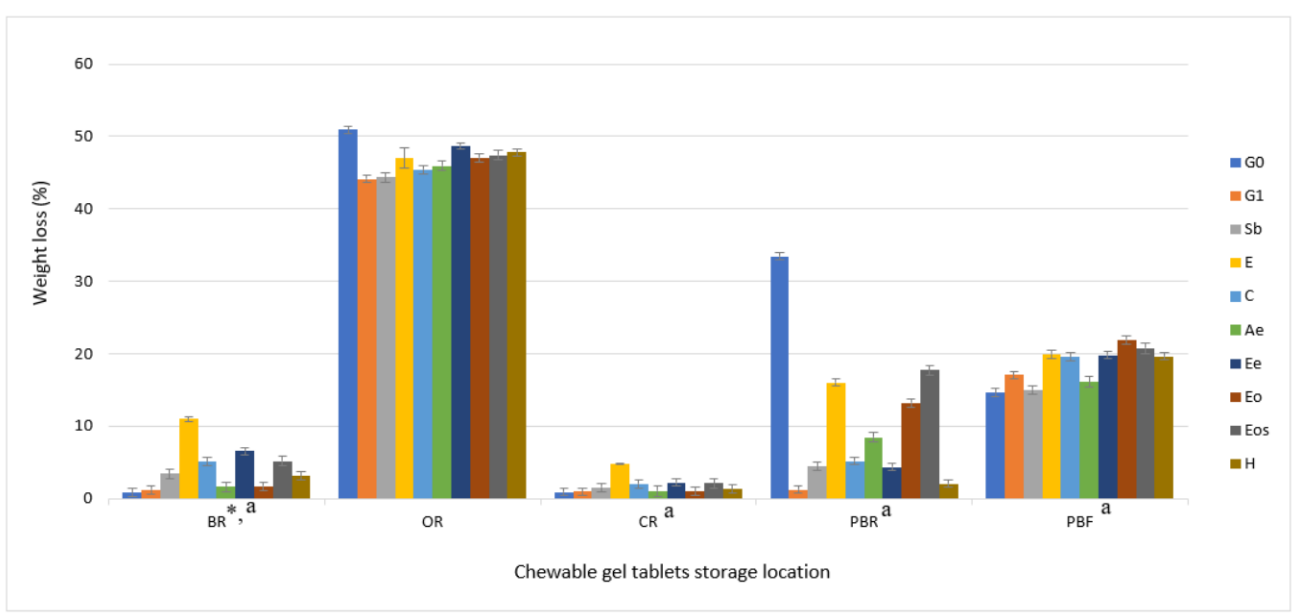

Figure 4. Dependence of changes in the mass of chewable gel tablets on storage conditions, $n=8$. * the change in mass was calculated from the last results before appearance of mold; $\mathrm{a}-p<0.05$ vs. OR conditions.

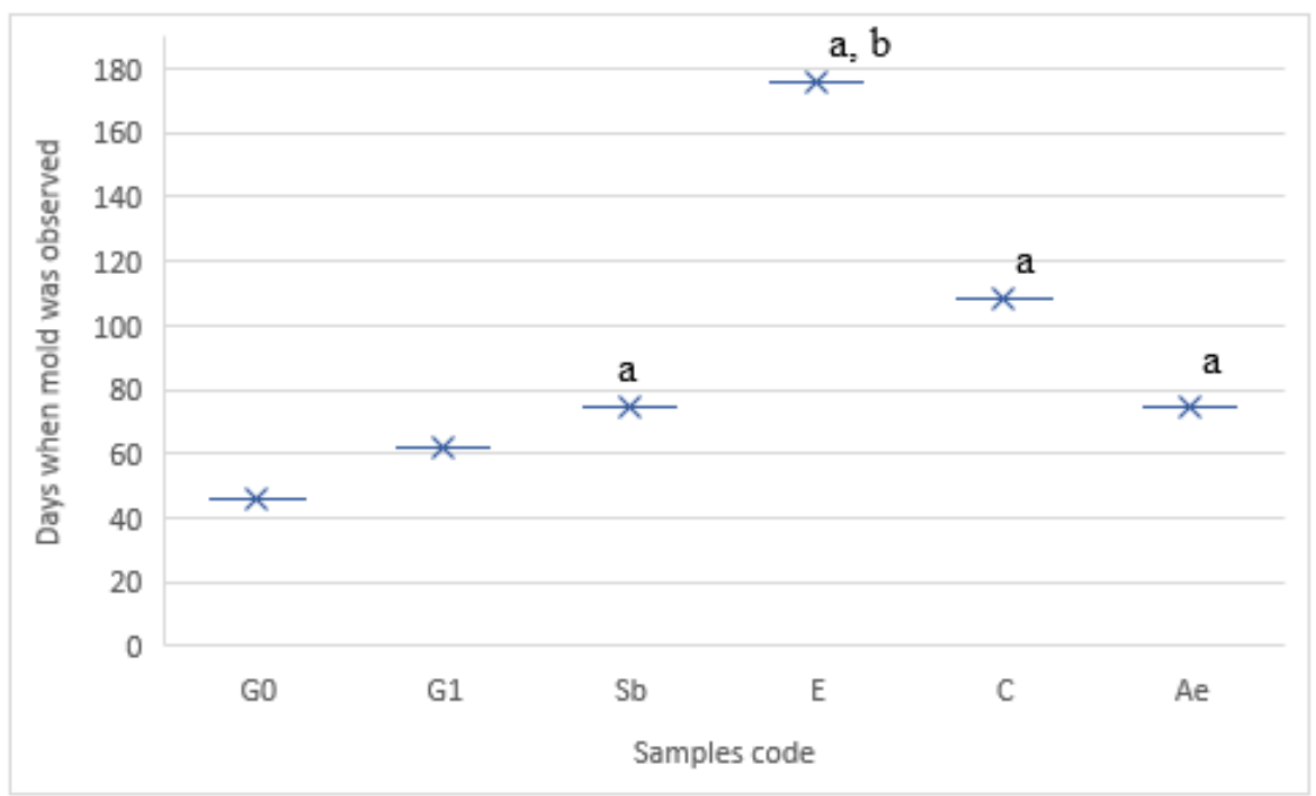

Figure 5. Chewable gel tablets shelf-life in a closed plastic box at room temperature (CR). $a-p<0.05$ vs. G1; $\mathrm{b}-p<0.05$ vs. $C ; n=8$; * study duration was 180 days; Ee, Eo, and Eos did not have a mold after 180 days, these samples are not presented in this figure.

Eight chewable gel tablets of every composition were kept in separate plastic bags and the number of days until mold had grown on the tablet was determined. When mold was seen on gel tablets in the plastic bag, the study was stopped.

The bacterial contamination tests were completed for equipment, devices and containers (Table 2). The amount of detected microorganisms was not higher than allowed. Less than $1.0 \times 10^{1}$ of TAMC (total aerobic microbial count) and TYMC (total mold and yeast count) were found, other organisms were not found. In the Ratajczak et al. (2014) study it was determined that some of the pharmaceutical products with raw materials or herbal medicinal products have a higher risk of microbial contamination [50]. Therefore, it is important to use good manufacturing practice rules for the development of products. 
Table 2. Chewable gel tablets' composition.

\begin{tabular}{|c|c|c|}
\hline Micro-Organisms & $\begin{array}{c}\text { Equipment and Devices (Scales, } \\
\text { Texture Analyzer, Tweezers, Silicone } \\
\text { Form and etc.) }\end{array}$ & $\begin{array}{l}\text { Containers (Plastic Box) } \\
\text { (the Plastic Squeezable Bag Was Not } \\
\text { Explored; It Was a Single-Use Plastic } \\
\text { Bag, Taken Straight from the Supplier } \\
\text { Box (Non-Contaminated)) }\end{array}$ \\
\hline TAMC & $<1.0 \times 10^{1}$ & $<1.0 \times 10^{1}$ \\
\hline TYMC & $<1.0 \times 10^{1}$ & $<1.0 \times 10^{1}$ \\
\hline Bile-tolerant gram-negative bacteria & not detected & not detected \\
\hline Salmonella spp. & not detected & not detected \\
\hline Escherichia coli & not detected & not detected \\
\hline Staphylococcus aureus & not detected & not detected \\
\hline
\end{tabular}

To compare storage conditions and containers, the opened plastic bag (OR) had the highest influence on the weight loss of gel tablets, all samples lost over $40 \%$ of mass and it was determined that glycerol significantly protects chewable gel tablets from weight loss when the tablets are in an open-air container. Temperature below zero (PBF) has an influence on water separation from gel tablets base-as was determined when they were left in a room temperature for $30 \mathrm{~min}$ (Figure 6). The safest containers to hold chewable gel tablets mass' uniformity is an airtight box (CR). These storage conditions have the smallest influence on weight loss and a higher influence on shelf-life (Figure 3).
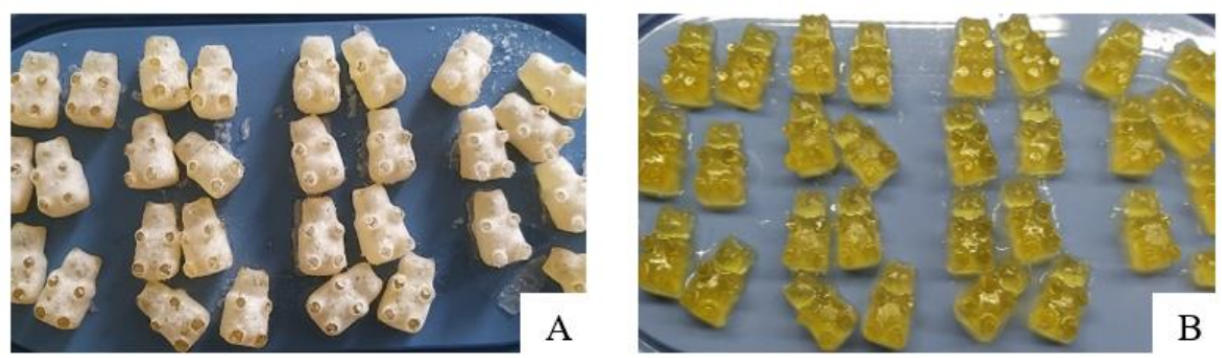

Figure 6. Chewable gel tablets taken out of freezer (A) and after $30 \mathrm{~min}$ at room temperature (B), tablets' amount per one series is $n=8$.

In Figure 6, four different formulations of tablets are shown, one formulation has 8 tablets (from each series of each gelatin-based tablets formulations for chosen storage conditions) with which the studies have been performed.

Ethanol and ethanolic nutmeg extracts in a composition of chewable gel tablets (E, Ee, Eos) have a higher influence on mass loss compared to other samples because they evaporate. However, these excipients significantly increased shelf-life of gel tablets (Figure 5).

Chewable gel tablets with nutmeg essential oil or extract had a longer shelf-life than other tablets. Ee, Eo, and Eos samples' shelf-life was over 180 days. They all had nutmeg as a preservative. Nutmeg essential oil has influence on microorganism growth suppression, $0.2 \%$ of essential oil suppressed the growth of Pasteurella multodica [32]. The most likely to mold tablets are those that did not contain preservatives and glycerol (G0 and G1). The shelf-life of the tablets that contained sodium benzoate was the same as the tablets containing aqueous nutmeg extract (in Figure 3, gel tablets in a squeezable bag with growing molds are presented). The chewable gel tablets with citric acid had a higher influence on protection from mold growth than sodium benzoate, which is usually used as a preservative in food or pharmacy industries. Sodium benzoate is an artificial preservative which has negative effects on health, it can be dangerous and can cause asthma, cancer, and hypersensivity [51]. It is used in concentrations of $0.02-0.5 \%$ in oral medicines [52]. So, this study shows that sodium benzoate $(0.096 \%)$ can be replaced by aqueous nutmeg extract $(1.92 \%)$, nutmeg hydrolat $(1.92 \%)$ or citric acid $(0.96 \%)$, which have similar or better effects against mold (Figure 5). 
Cinnamon, cloves, rosemary extract, grapefruit extract and other spices, herbs or fruits can be used as natural preservatives [4,53]. Thyme extract was chosen as a taste additive but it also has antiseptic and antifungal activities [46]. In the study by Bartkiene at al. (2018), Thymus vulgaris essential oil had a higher effect against such microorganisms as C. paradisi, C. recutita, and Eugenia caryophyllata than other essential oils in gummy candies, such as cloves essential oil. The essential oil's concentration ranged from $0.1 \%$ to $0.4 \%$ or an essential oil emulsion with modified waxy maize starch was used, which contained $12 \%$ of essential oil [8].

Citric acid is used as an antioxidant, a preservative and a taste coregent in hard candies at a concentration of $0-1 \%$ [54] and in gummy candies from $2.5 \%$ to $4.5 \%$ [55]. In this study, $0.96 \%$ citric acid concentration was not only used as a preservative for the chewable gel tablets but also to produce a better taste. Finally, this concentration was more effective than sodium benzoate.

\subsection{Chewable Gel Tablets' Firmness and Springiness}

To determine the preservatives' influence on the chewable gel tablets' texture, a study was prepared where the firmness and springiness of the gel tablets were measured in OR storage conditions. Firmness is a parameter which shows chewable gel tablet's strength and tightness. In this study it was measured how much strength is needed to compress 50\% of gel tablet's height. In Figure 7 the change of firmness is shown. Chewable gel tablets without glycerol (G0) had a higher firmness-from $426.45 \pm 20.03 \mathrm{~g}$ to over $6500 \mathrm{~g}$ (the analyzer did not measure the correct value). After 24 hours, the firmness of the gel tablets with preservatives was measured and it was determined that aqueous extract of nutmeg (Ae), ethanolic extract of nutmeg (Ee), and nutmeg hydrolat statistically significantly increased the firmness by about $16.64 \pm 7.76 \%$, but sodium benzoate (Sb), citric acid (C), nutmeg essential oil (Eo), and essential oil solution (Eos) significantly decreased the firmness by about $24.86 \pm 9.90 \%$ compared to the G1 sample. To compare the preservatives' influence on firmness after 28 days, it was determined that the force needed to compress the gel tablets by $50 \%$ of $\mathrm{H}, \mathrm{C}$, and Ee samples was significantly higher than in the G1 sample $(2164.87 \pm 249.25 \mathrm{~g}, 1674.25 \pm 125.34 \mathrm{~g}$, and $1556.5 \pm 155.46 \mathrm{~g}$ vs. $1188.2 \pm 128.96 \mathrm{~g})$. Other results did not show a statistically significant change after 28 days (Figure 7).

When evaluating springiness (parameter which shows elasticity) in the chewable gel tablets with preservatives, it was determined that nutmeg hydrolat had a statistically significant influence on lower springiness for both just made and 28-day-old gel tablets (31.61\% and 28.45\% lower to compared with G1). After 24 hours, sodium benzoate (Sb) and a sample with ethanolic nutmeg extract (Ee) also had a statistically significantly decreased springiness from $74.09 \pm 3.46 \%$ (G1) to $52.02 \pm 2.69$ and $38.30 \pm 3.23 \%$ (Figure 8 ).

Evaluating the results of the chewable gel tablets' textures, which were achieved with different preservatives, it can be concluded that the tablets' firmness increase nearly 4 times and springiness decreased by about 1.65 times when kept in such storage conditions as an opened plastic box at room temperature. In the study by Bartkienè et al. (2018), gummy candies' hardness, gumminess, and chewiness were measured. When thyme or cloves essential oil ( $0.2 \%)$ were added to the gummies, the hardness decreased from about 5400 to $2900 \mathrm{~g}$ (thyme) and to $3400 \mathrm{~g}$ (cloves), the gumminess decreased by about 1.3 times and the chewiness increased by about 1.14 and 1.08 times [8]. In the study by Čižauskaitè et al. (2019) where gummy bears with vitamin D3 and calcium carbonate were prepared, the texture variation was determined. Statistically significant results of decreasing firmness, strength, and hardness were obtained when active substances were added. The firmness decreased over $50 \%$, hardness-about 30\%, strength-about $40 \%$ [4]. 


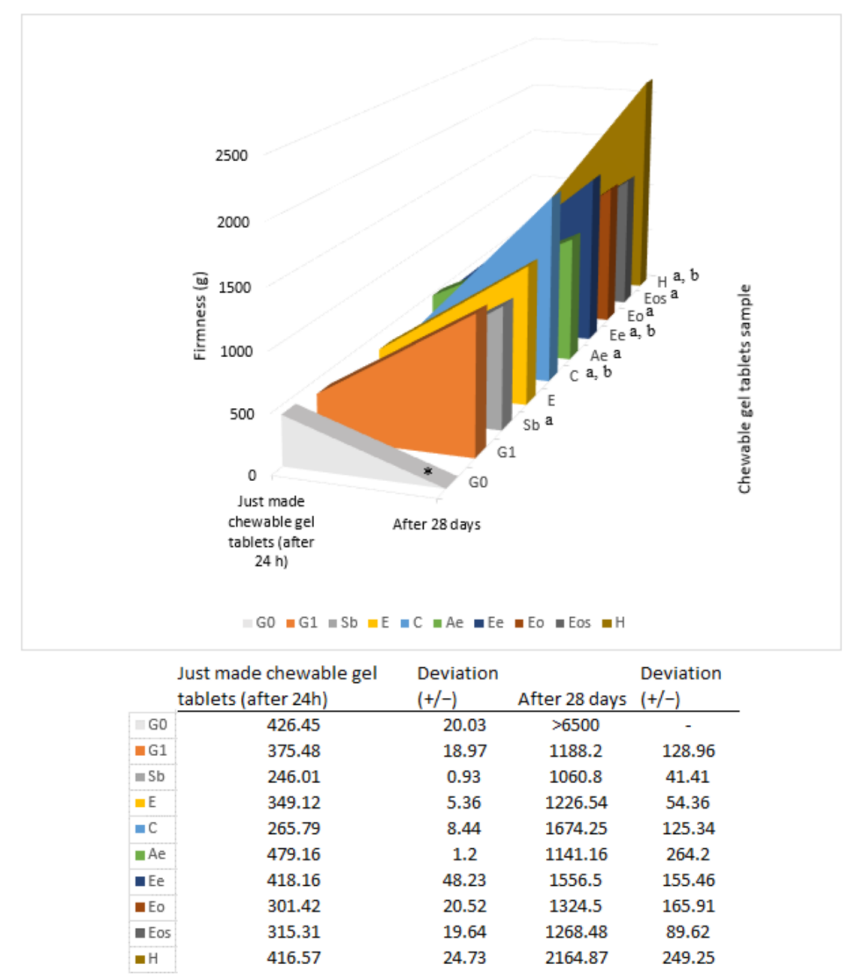

Figure 7. Firmness changes in chewable gel tablets after 28 days kept at room temperature in an open plastic bag. * Device did not measure value after 28 days, it was higher than $6500 \mathrm{~g}$, a statistically significant change after $24 \mathrm{~h}$ vs. G1; b-statistically significant change after 28 days vs. G1, $p<0.05$, $n=8$.

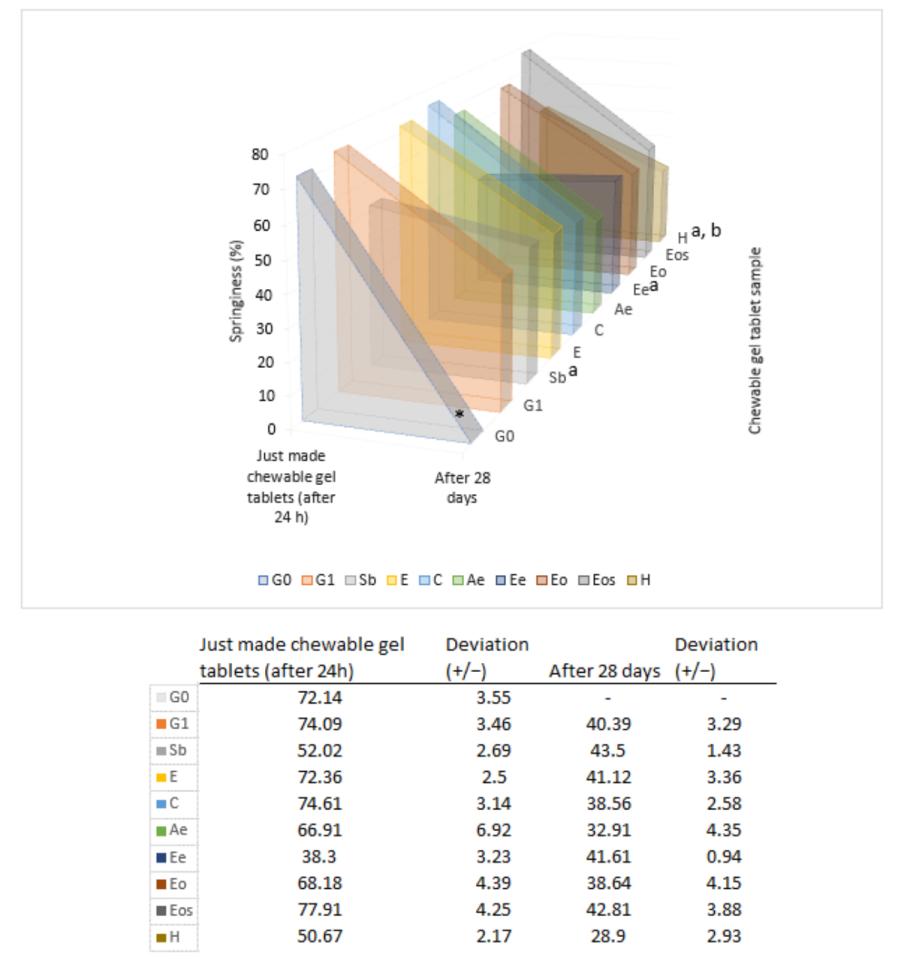

Figure 8. Springiness' change in chewable gel tablets after 28 days kept at room temperature in an open plastic bag. * Device did not measure value after 28 days, a statistically significant change after 24 h vs. G1; b-statistically significant change after 28 days vs. G1, $p<0.05, n=8$. 
The texture of the chewable gel tablets is affected not only by storage conditions but also by excipients and active ingredients.

The study with nutmeg seed products as a preservative is the beginning of many studies of the future where natural materials (plants, herbs, seeds) can be used as natural preservatives in solid medicines forms (such as gel tablets which have water in their composition). Additionally, these materials can modify tablets' texture properties so the results can be used for the manufacture of chewable gel tablets. Another benefit of natural materials from plants is that extracts and essential oils have a pharmacological effect and can be used as synergistic materials together with pharmaceutical substances.

\section{Conclusions}

After the production of 10 different formulations of chewable gel tablets, it was found that their shelf-life was influenced not only by the choice of preservative but also by the storage conditions. The chewable gel tablets are most likely to become molded in squeezable bags, and the most suitable tablets for use were stored in tightly closed boxes. When gel tablets were stored in the freezer and then left at room temperature for $30 \mathrm{~min}$, they lost part of water, which is visible next to the tablets; and when stored in an open plastic box they lost part of their weight and hardened. The best way to store gel tablets is in a sealed box.

Nutmeg essential oil and its solution, ethanolic nutmeg extract were better preservatives for chewable gel tablets than sodium benzoate or citric acid $(p<0.05)$. The shelf-life (in a closed plastic box at room temperature) of these gel tablets (with nutmeg seed product) was more than 62 days longer compared to gel tablets containing citric acid $(0.96 \%)$ solution.

Nutmeg hydrolat had the biggest influence on texture as a preservative. It increased the gel tablets' firmness by about 1.8 times and decreased elasticity by about 1.4 times compared to the tablets without preservatives after 28 days of study $(p<0.05)$. The gel tablets without glycerol are incompressible and very hard after 28 days, therefore, glycerol is required as a protector from weight loss.

This study shows that a natural preservative (nutmeg seed products) can substitute chemical preservatives and protect gelatin-based tablets from mold and prolong the shelflife of tablets. These data are the basis for further research into the use of natural substances (extracts, essential oil) in the protection of medicines or other forms (food supplements) against mold and the additional exploitation of the pharmacological effects of plants.

Author Contributions: Conceptualization, J.B., I.M., S.V. and A.M.; methodology, I.M.; formal analysis, I.M. and J.B.; investigation, I.M.; data curation, J.B.; writing — original draft preparation, I.M.; writing-review and editing, J.B., A.M., S.V. and I.M.; visualization, J.B. and I.M.; supervision, J.B. All authors have read and agreed to the published version of the manuscript.

Funding: This research received no external funding.

Institutional Review Board Statement: Not applicable.

Informed Consent Statement: Not applicable.

Data Availability Statement: The data presented in this study are available on request from the corresponding author.

Acknowledgments: The authors would like to thank Open Access Centre for the Advanced Pharmaceutical and Health Technologies (Lithuanian university of Health Sciences) and for the opportunity to use modern infrastructure and perform this research.

Conflicts of Interest: The authors declare no conflict of interest.

\section{References}

1. Nyamweya, N.N.; Kimani, S.N. Chewable Tablets: A Review of Formulation Considerations. Pharm. Technol. 2020, 44, 38-44.

2. Taranum, R.; Mittapally, S. Soft Chewable Drug Delivery System: Oral Medicated Jelly and Soft Chew. J. Drug Deliv. Ther. 2018, 8, 65-72. [CrossRef] 
3. World Health Organization. World Health Organization Model List of Essential Medicines; World Health Organization: Genève, Switzerland, 2019; pp. 1-6.

4. Čižauskaitè, U.; Jakubaitytè, G.; Žitkevičius, V.; Kasparavičienè, G. Natural Ingredients-Based Gummy Bear Composition Designed According to Texture Analysis and Sensory Evaluation in Vivo. Molecules 2019, 24, 1442. [CrossRef] [PubMed]

5. DeMars, L.L.; Ziegler, G.R. Texture and Structure of Gelatin/Pectin-Based Gummy Confections. Food Hydrocoll. 2001, 15, 643-653. [CrossRef]

6. European Pharmacopoeia. Tablets Compressi. In European Pharmacopoeia 10.3; European Medicines Agency: Amsterdam, The Netherlands, 2018; pp. 937-939.

7. Bhusnure, O.G.; Shaikh, F.E.; Sugave, B.K.; Kavale, B.S.; Sayyed, R.A.; Hucche, B.S. Formulation Strategies for Taste-Masking of Chewable Tablets. Indo Am. J. Pharm. Res. 2015, 5, 3836-3849.

8. Bartkiene, E.; Ruzauskas, M.; Lele, V.; Zavistanaviciute, P.; Bernatoniene, J.; Jakstas, V.; Ivanauskas, L.; Zadeike, D.; Klupsaite, D.; Viskelis, P.; et al. Development of Antimicrobial Gummy Candies with Addition of Bovine Colostrum, Essential Oils and Probiotics. Int. J. Food Sci. Technol. 2018, 53, 1227-1235. [CrossRef]

9. Wright, D.J.; Potter, J.F.; Clark, A.; Blyth, A.; Maskrey, V.; Mencarelli, G.; Wicks, S.O.; Craig, D.Q.M. Administration of Aspirin Tablets Using a Novel Gel-Based Swallowing Aid: An Open-Label Randomised Controlled Cross-over Trial. BMJ Innov. 2019, 5, 113-119. [CrossRef] [PubMed]

10. Schrieber, R.; Gareis, H. Gelatine Handbook. Theory and Industrial Practice; WILEY-VCH Verlag GmbH \& Co. KgaA: Weinheim, Germany, 2007.

11. Karim, A.A.; Bhat, R. Fish Gelatin: Properties, Challenges, and Prospects as an Alternative to Mammalian Gelatins. Food Hydrocoll. 2009, 23, 563-576. [CrossRef]

12. Gomez-Guillen, M.C.; Gimenez, B.; Lopez-Caballero, M.E.; Montero, M.P. Functional and Bioactive Properties of Collagen and Gelatin from Alternative Sources: A Review. Food Hydrocoll. 2011, 25, 1813-1827. [CrossRef]

13. Pinson, M.L.; Waibel, K.H. Safe Administration of a Gelatin-Containing Vaccine in an Adult with Galactose- $\alpha-1,3-G a l a c t o s e$ Allergy. Vaccine 2015, 33, 1231-1232. [CrossRef]

14. Michon, C.; Cuvelier, G.; Launay, B. Concentration Dependence of the Critical Viscoelastic Properties of Gelatin at the Gel Point. Rheol. Acta 1993, 32, 94-103. [CrossRef]

15. Rivero, R.; Archaina, D.; Sosa, N.; Leiva, G.; Baldi Coronel, B.; Schebor, C. Development of Healthy Gummy Jellies Containing Honey and Propolis. J. Sci. Food Agric. 2020, 100, 1030-1037. [CrossRef] [PubMed]

16. Cai, L.; Feng, J.; Regenstein, J.; Lv, Y.; Li, J. Confectionery Gels: Effects of Low Calorie Sweeteners on the Rheological Properties and Microstructure of Fish Gelatin. Food Hydrocoll. 2017, 67, 157-165. [CrossRef]

17. Tong, Q.; Xiao, Q.; Lim, L.T. Effects of Glycerol, Sorbitol, Xylitol and Fructose Plasticisers on Mechanical and Moisture Barrier Properties of Pullulan-Alginate-Carboxymethylcellulose Blend Films. Int. J. Food Sci. Technol. 2013, 48, 870-878. [CrossRef]

18. Neacsu, N.A.; Madar, A. Artificial Sweeteners versus Natural Sweeteners. Bull. Transilv. Univ. Brasov 2014, 7, 59-64.

19. Ramesh, M.; Muthuramas, A. Flavoring and Coloring Agents: Health Risk and Potential Problems. In Natural and artificial Flavoring Agents and Food Dyes; Grumezescu, A.M., Holban, A.M., Eds.; Academic Press: Cambridge, MA, USA, 2018 ; pp. 1-29.

20. Damle, M.C.; Bhalekar, M.R.; Rao, S.; Godse, M. Formulation and Evaluation of Chewable Tablets of Pomegranate Peel Extract. J. Drug Deliv. Ther. 2019, 9, 318-321.

21. Abdulmumeen, H.A.; Risikat, A.N.; Sururah, A.R. Food: Its Preservatives, Additives and Applications. Int. J. Chem. Biochm. Sci. 2012, 1, 36-47.

22. Nishad, J.; Koley, T.K.; Varghese, E.; Kaur, C. Synergistic Effects of Nutmeg and Citrus Peel Extracts in Imparting Oxidative Stability in Meat Balls. Food Res. Int. 2018, 106, 1026-1036. [CrossRef] [PubMed]

23. Madhumita, R.; Ramalingam, C. Gum Acacia Coating with Garlic and Cinnamon as an Alternate, Natural Preservative for Meat and Fish. African J. Biotechnol. 2013, 12, 406-413. [CrossRef]

24. Kordsardouei, H.; Barzegar, M.; Sahari, M.A. Application of Zataria Multiflora Boiss. and Cinnamon Zeylanicum Essential Oils as Two Natural Preservatives in Cake. Avicenna J. Phytomed. 2013, 3, 238-247. [CrossRef]

25. Mugoyela, V.; Mugoyela, V.; Mwambete, K.D. Microbial Contamination of Nonsterile Pharmaceuticals in Public Hospital Settings. Ther. Clin. Risk Manag. 2010, 443. [CrossRef]

26. Jimenez, L. Microbial Contamination Control in the Pharmaceutical Industry; Marcel Dekker: New York, NY, USA, 2004.

27. Donald, J. Prevention of Microbial Contamination on Manufacturing. In Cosmetic Microbiology—A Practical Approach; CRC Press: Boca Raton, FL, USA, 2020; pp. 57-71.

28. Abourashed, E.A.; El-Alfy, A.T. Chemical Diversity and Pharmacological Significance of the Secondary Metabolites of Nutmeg (Myristica Fragrans Houtt). Phytochem. Rev. 2016, 15, 1035-1056. [CrossRef] [PubMed]

29. Sanghai-Vaijwade, D.N.; Kulkarni, S.R.; Sanghai, N.N. Nutmeg: A Promising Antibacterial Agent for Stability of Sweets. Int. J. Research Pharm. Chem. 2011, 1, 403-407.

30. Takikawa, A.; Abe, K.; Yamamoto, M.; Ishimaru, S.; Yasui, M.; Okubo, Y.; Yokoigawa, K. Antimicrobial Activity of Nutmeg against Escherichia Coli O157. J. Biosci. Bioeng. 2002, 94, 315-320. [CrossRef]

31. Firouzi, R.; Shekarforoush, S.S.; Nazer, A.H.; Borumand, Z.; Jooyandeh, A.R. Effects of Essential Oils of Oregano and Nutmeg on Growth and Survival of Yersinia Enterocolitica and Listeria Monocytogenes in Barbecued Chicken. J. Food Prot. 2007, 70, 2626-2630. [CrossRef] 
32. Matulyte, I.; Jekabsone, A.; Jankauskaite, L.; Zavistanaviciute, P.; Sakiene, V.; Bartkiene, E.; Ruzauskas, M.; Kopustinskiene, D.M.; Santini, A.; Bernatoniene, J. The Essential Oil and Hydrolats from Myristica Fragrans Seeds with Magnesium Aluminometasilicate. Foods 2020, 9, 37. [CrossRef]

33. Komiyama, E.Y.; Lepesqueur, L.S.S.; Yassuda, C.G.; Samaranayake, L.P.; Parahitiyawa, N.B.; Balducci, I.; Koga-Ito, C.Y. Enterococcus Species in the Oral Cavity: Prevalence, Virulence Factors and Antimicrobial Susceptibility. PLoS ONE 2016, 11. [CrossRef] [PubMed]

34. Pinheiro, E.T.; Mayer, M.P.A. Enterococcus Faecalis in Oral Infections. JBR J. Interdiscip. Med. Dent. Sci. 2014, 3, 1-5.

35. Embuscado, M.E. Spices and Herbs: Natural Sources of Antioxidants-A Mini Review. J. Funct. Foods 2015, 18, 811-819. [CrossRef]

36. Matulyte, I.; Marksa, M.; Ivanauskas, L.; Kalvenien e, Z.; Lazauskas, R.; Bernatoniene, J. GC-MS Analysis of the Composition of the Extracts and Essential Oil from Myristica Fragrans Seeds Using Magnesium Aluminometasilicate as Excipient. Molecules 2019, 24, 1062. [CrossRef]

37. European Pharmacopoeia. Microbiological Examination of Non-Sterile Products: Test for Specified Micro-Organisms. In Europoean Pharmacopoeia 10.3; European Medicines Agency: Amsterdam, The Netherlands, 2018; pp. 167-171.

38. European Pharmacopoeia. Microbiological Quality of Non-Sterile Pharmaceutical Preparations Ans Substances for Pharmaceutical Use. In Europoean Pharmacopoeia 10.3; European Medicines Agency: Amsterdam, The Netherlands, 2018 ; pp. 579-580.

39. Morten, J.D.; Magnus, H.N.; Kurt, D.I. Soft, Chewable Gelatin-Based Pharmaceutical Oral Formulations: A Technical Approach. Pharm. Dev. Technol. 2018, 23, 504-511. [CrossRef]

40. Pizzoni, D.; Compagnone, D.; Di Natale, C.; D'Alessandro, N.; Pittia, P. Evaluation of Aroma Release of Gummy Candies Added with Strawberry Flavours by Gas-Chromatography/Mass-Spectrometry and Gas Sensors Arrays. J. Food Eng. 2015, 167, 77-86. [CrossRef]

41. Déléris, I.; Saint-Eve, A.; Dakowski, F.; Sémon, E.; Le Quéré, J.L.; Guillemin, H.; Souchon, I. The Dynamics of Aroma Release during Consumption of Candies of Different Structures, and Relationship with Temporal Perception. Food Chem. 2011, 127, 1615-1624. [CrossRef]

42. Farahni, A.; Ansari, S.; Majzobi, M. Effect of Glycerol and Glucose Syrup on Sugar Crystallization in Figs. J. Sci. Technol. Agric. Nat. Resour. Source 2009, 1.

43. Ballmann, C.; Müeller, B.W. Stabilizing Effect of Cetostearyl Alcohol and Glycerylmonstearate as Co-Emulsifiers on HydrocarbonFree O/W Glyceride Creams. Pharm. Dev. Technol. 2008, 13, 433-445. [CrossRef] [PubMed]

44. Kholif, A.E. Glycerol Use in Dairy Diets: A Systemic Review. Anim. Nutr. 2019, 5, 209-216. [CrossRef]

45. Dauqan, E.M.A.; Abdullah, A. Medicinal and Functional Values of Thyme (Thymus Vulgaris L.) Herb. J. Appl. Biol. Biotechnol. 2017, 5, 17-22. [CrossRef]

46. Zekovic, Z.P.; Lepojevic, Z.D.; Miloševič, S.; Markov, S.L. Tablets with Thyme (Thymus Vulgaris L.) Extracts. Acta Period. Technol. 2002, 33, 159-165. [CrossRef]

47. Ramos, Ó.L.; Reinas, I.; Silva, S.I.; Fernandes, J.C.; Cerqueira, M.A.; Pereira, R.N.; Vicente, A.A.; Poças, M.F.; Pintado, M.E.; Malcata, F.X. Effect of Whey Protein Purity and Glycerol Content upon Physical Properties of Edible Films Manufactured Therefrom. Food Hydrocoll. 2013, 30, 110-122. [CrossRef]

48. Engineering ToolBox, Glycerine-Boiling and Freezing Points. Available online: https://www.engineeringtoolbox.com/glycerineboiling-freezing-points-d__1590.html (accessed on 3 February 2021).

49. Lane, L.B. Freezing Points of Glycerol and Its Aqueous Solutions. Ind. Eng. Chem. 1925, 17, 924. [CrossRef]

50. Ratajczak, M.; Kubicka, M.M.; Kamińska, D.; Sawicka, P.; Długaszewska, J. Microbiological Quality of Non-Sterile Pharmaceutical Products. Saudi Pharm. J. 2015, 23, 303-307. [CrossRef] [PubMed]

51. Anand, S.P.; Sati, N. Artificial Preservatives and Their Harmful Effects: Looking Toward Nature for Safer Alternatives. Int. J. Pharm. Sci. Res. IJPSR 2013, 4, 2496-2501. [CrossRef]

52. Shaikh, S.M.; Doijad, R.C.; Shete, A.S.; Sankpal, P.S. A Review on: Preservatives Used in Pharmaceuticals and Impacts on Health. PharmaTutor 2016, 4, 25-34.

53. Dwivedi, S.; Prajapati, P.; Vyas, N.; Malviya, S.; Kharia, A. A Review on Food Preservation: Methods, Harmful Effects and Better Alternatives. Asian J. Pharm. Pharmacol. 2017, 3, 193-199.

54. Netramai, S.; Kijchavengkul, T.; Sompoo, P.; Kungnimit, W. The Effect of Intrinsic and Extrinsic Factors on Moisture Sorption Characteristics of Hard Candy. J. Food Process. Preserv. 2018, 42, 1-7. [CrossRef]

55. Zhang, Y.; Barringer, S. Effect of Hydrocolloids, Sugar, and Citric Acid on Strawberry Volatiles in a Gummy Candy. J. Food Process. Preserv. 2018, 42, 1-8. [CrossRef] 